\title{
ROLE OF RELATIONSHIP MARKETING IN PROMOTING SMART TECHNOLOGIES IN THE HOUSING AND UTILITIES MARKET
}

\author{
Svetlana V. Fedorova \\ Volgograd State University, Volgograd, Russian Federation
}

\begin{abstract}
The purpose of the study is to determine the criteria for segmentation of consumers of housing and communal services and build a model of their needs as a basis for the formation of marketing relationships for the management organization in order to increase the effectiveness of the introduction of smart technologies in the housing and communal services market. The introduction of smart technologies in the sphere of housing and communal services directly depends on the development of the relationship marketing as a technology for coordinating interests of all stakeholders in the market under consideration. In relation to the market of housing and communal services (HCS), the relationship marketing has been studied very little, which is due to the weak development of the categorical and methodological apparatus of the concept itself, as well as the complexity and multidimensionality of the subject-object structure of the housing and communal services market as an object of research. The housing and utilities market is a complex system that includes two clusters: the utility and housing segments which differ in service parameters, market types, and the composition of market entities. The article analyzes key barriers to the introduction of smart technologies in the market of housing and communal services. Besides, the segmentation of consumers is carried out; a model of the hierarchy of needs of consumers of housing and communal services is proposed; the relationship between the needs and the selection of specific smart technologies for managing an apartment building is revealed.

Key words: housing and communal service, target segments, needs, relationship marketing, competitive mechanism.

Citation. Fedorova S.V. Role of Relationship Marketing in Promoting Smart Technologies in the Housing and Utilities Market. Journal of Volgograd State University. Economics, 2020, vol. 22, no. 2, pp. 161-170. (in Russian). DOI: https://doi.org/10.15688/ek.jvolsu.2020.2.15
\end{abstract}

УДК 332

ББК 65.441
Дата поступления статьи: 03.03.2020

Дата принятия статьи: 20.03.2020

\section{РОЛЬ МАРКЕТИНГА ВЗАИМООТНОШЕНИЙ \\ В ПРОДВИЖЕНИИ УМНЫХ ТЕХНОЛОГИЙ НА РЫНКЕ УСЛУГ ЖИЛИЩНО-КОММУНАЛЬНОГО ХОЗЯЙСТВА}

\section{Светлана Владимировна Федорова}

Волгоградский государственный университет, г. Волгоград, Российская Федерация

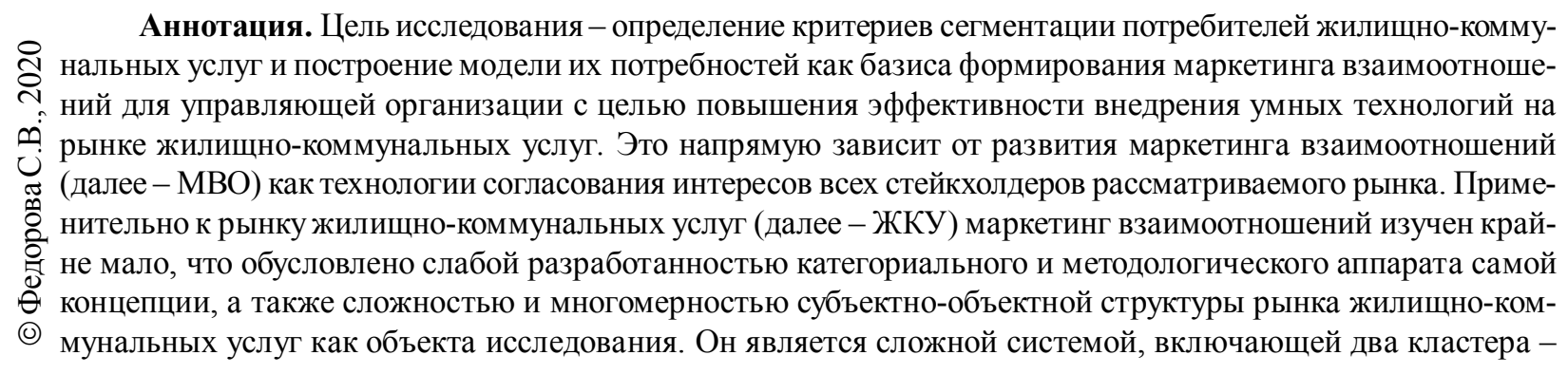


коммунальный и жилищный сегменты, различающиеся параметрами услуг, типами рынков, составом рыночных субъектов. В статье анализируются ключевые барьеры внедрения умных технологий на рынке жилищно-коммунальных услуг, осуществляется сегментация потребителей, предлагается модель иерархии нужд потребителей жилищно-коммунальных услуг, выявляется зависимость между потребностями и отбором конкретных умных технологий управления многоквартирным домом.

Ключевые слова: жилищно-коммунальная услуга, целевые сегменты, потребности, маркетинг взаимоотношений, конкурентный механизм.

Цитирование. Федорова С. В. Роль маркетинга взаимоотношений в продвижении умных технологий на рынке услуг жилищно-коммунального хозяйства // Вестник Волгоградского государственного университета. Экономика. -2020. - Т. 22, № 2. - C. 161-170. -DOI: https://doi.org/10.15688/ek.jvolsu.2020.2.15

\section{Введение}

Актуальность темы исследования обусловлена тем, что, несмотря на остро назревшую необходимость внедрения рыночных механизмов в сферу ЖКХ, можно утверждать, что маркетинговые инструменты в данном секторе находятся на начальном этапе формирования.

Сегмент коммунальных услуг рынка ЖКУ охватывает взаимоотношения управляющих компаний, обслуживающих жилой фонд, с естественными монополиями, осуществляющими ресурсообеспечение (водоснабжение и водоотведение, газо- и теплоснабжение, электроснабжение, а с 2019 г. - обращение с твердыми коммунальными отходами (ТКО)). Крайняя степень монополизации данного сегмента и законодательные регламенты практически исключают возможность применения маркетингового инструментария во взаимоотношениях «поставщик ресурсов - управляющая организация».

Рыночный сегмент жилищных услуг охватывает взаимоотношения «управляющая организация - потребитель ЖКУ» и является зоной конкурентной борьбы за потребителя и, соответственно, представляет собой большой потенциал для реализации маркетинговых усилий и построения долгосрочных и взаимовыгодных взаимоотношений с потребителями.

При этом анализ эволюции положений Жилищного Кодекса РФ позволяет сделать вывод, что законодатель последовательно идет по пути все большего наделения потребителей ЖКУ весомыми рычагами воздействия на управляющие организации, вплоть до их смены. Поэтому дальнейшее развитие рынка ЖКУ, а также развитие умных технологий в данной сфере, может идти только по пути внедрения в работу управляющей организации современных инструментов маркетинга взаимоотношений.

Эффективность развития умных технологий в данном секторе полностью определяется запросами и предпочтениями потребителей, степенью их удовлетворенности и вовлеченности в развитие данного сектора, а непосредственно отбор, финансирование и внедрение умных технологий в управление многоквартирными домами де-юре невозможны без согласования с жильцами на общих собраниях собственников. Однако, как показывает современная российская практика, управляющие организации, в том числе управляющие компании (далее - УК), товарищества собственников жилья (далее ТСЖ), товарищества собственников недвижимости (далее- ТСН), жилищно-строительные кооперативы (далее - ЖСК) практически не используют детерминанты потребительского поведения как базис для моделирования процесса принятия управленческих решений, что является практически непреодолимым препятствием на пути внедрения умных технологий в управление многоквартирными домами.

\section{Методология исследования}

Обоснование теоретических положений осуществляется на основе реализации общенаучных подходов: диалектического, историко-логического, структурно-функционального; разработка практических рекомендаций - на основании традиционных (сегментация, приоритезация), а также современных маркетинговых методов маркетинговых исследований, таких как ситуационный анализ, наблюдение, 
экспертные оценки, метод графической интерпретации, контент-анализ и др.

Ряд выводов основан на результатах экспертной оценки, предпринятой автором и его профессиональным окружением, как непосредственными субъектами рынка ЖКУ, как формирующими спрос, так и участвующими, в силу своей практической деятельности, в управлении объектами жилищно-коммунального хозяйства.

\section{Результаты исследования}

Сфера жилищно-коммунального хозяйства считается консервативной и закрытой новым технологиям отраслью, характеризующейся значительным недофинансированием и, соответственно, большим числом технологическим проблем: высокий физический и моральный износ основных фондов ЖКХ; устаревшие технологии в эксплуатации инженерных сетей, неэффективные технологические решения и схемы предоставления ЖКУ [Бабкина].

Значительные трудности в данном секторе наблюдаются при переходе на энергосберегающие технологии. В России в настоящее время порядка $70 \%$ от общего потенциала энергосбережения страны расходуется именно в секторе ЖКХ, при этом энергоемкость отрасли более чем четырехкратно превосходит аналогичные средние показатели стран со сходным климатом [Коваль]. В жилищном секторе даже наиболее распространенные технологии: энергосберегающие светильники, датчики движения и освещенности, приборы учета ресурсов - внедряются в работу управляющей организации очень редко. Энергоаудит домов - крайне затратное мероприятие, а населению достаточно сложно объяснить целесообразность таких расходов [Fedorova et al., 2019].

К технологическим проблемам можно отнести и проблемы цифровизации в сфере ЖКХ. Сегодня существует множество умных цифровых решений для отрасли, однако механизмы реализации концепции цифровизации ЖКХ, как правовые, так и экономические, пока недостаточно проработаны, не говоря уже о высокой затратности подобных мероприятий, что является непреодолимым препятствиям для небольших УК и однодомных ТСЖ. Однако за цифровыми инновациями будущее [Цифровая Россия ... , 2017], поэтому в рамках маркетинга взаимоотношений в жилищном сегменте рынка необходимы мероприятия по вовлечению населения в массовое использование умных цифровых технологий. Непреодолимым барьером на пути внедрения умных технологий является сложившееся негативное отношение потребителей к сфере ЖКХ, неудовлетворенность качеством ЖКУ, низкая степень вовлеченности в развитие данного сектора. Так, по данным ВЦИОМ на сентябрь 2017 г., самые распространенные формы участия населения в реформе ЖКХ - установка индивидуальных приборов учета холодного и горячего водоснабжения (74 \%), энергосберегающих ламп (75\%) и участие в благоустройстве прилегающей к дому территории (24\%). Крайне низкая степень вовлеченности граждан отмечается в следующих вопросах: выбор способа формирования фонда капремонта дома (13\%), выбор УК и избрание совета дома (по 7 \%); участие в создании ТСЖ / ТСН (3\%); участие в контроле деятельности УК (4\%). Удовлетворенность качеством ЖКУ в целом по России - невысокая: $19 \%$ россиян считают, что ситуация в отрасли ухудшается [Осведомленность россиян ..., 2017].

Сложившаяся практика управления многоквартирными дамами позволяет выделить целый ряд управленческих и маркетинговых проблем, являющихся серьезными препятствиями на пути эффективных коммуникаций с потребителями (см. рис. 1).

Наличие указанных проблем приводит к проблемам во взаимодействии с потребителями ЖКУ, недоверию населения к субъектам ЖКХ, консервации негативных стереотипов в отношении деятельности всей отрасли, социальным конфликтам. Именно поэтому крайне актуальным становится внедрение маркетинга партнерских отношений в работу управляющих организаций.

Маркетинг взаимоотношений сегодня является последним этапом эволюционного развития маркетинга от концепции удовлетворения потребителей посредством однократных обменных сделок к концепции долгосрочных взаимовыгодных отношений с потребителями 


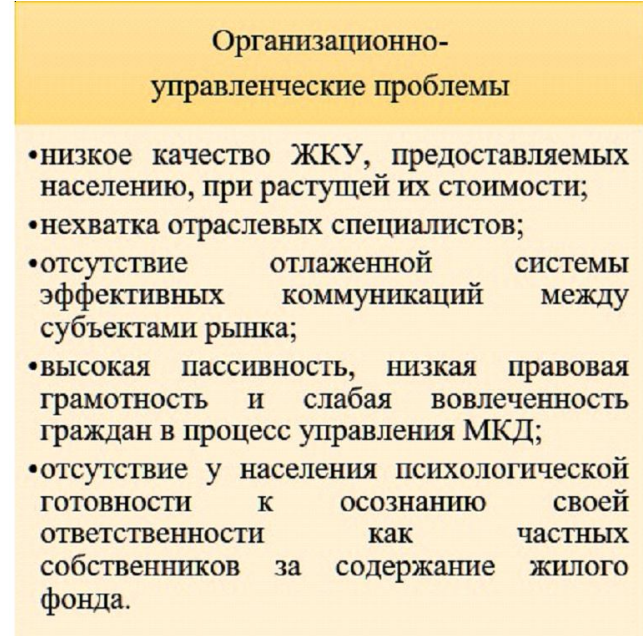

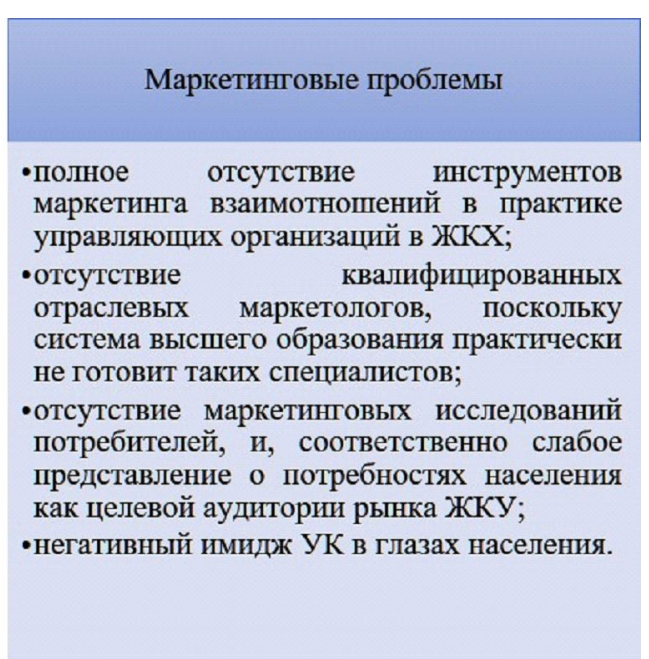

Рис. 1. Основные проблемы маркетинга взаимоотношений управляющих организаций с потребителями ЖКУ Примечание. Составлено автором.

с участием всех заинтересованных сторон [Бондаренко, 2015; Гембл и др., 2002; Bruhn, 2003; Shani et al., 1992].

В соответствии с новой парадигмой маркетинга клиенты рассматриваются как полноправные стейкхолдеры в цепочке создания новой ценности, а также как основной источник конкурентного преимущества фирмы [Таппасханова и др., 2017, с. 67].

Специфика системы стратегического планирования маркетинга взаимоотношений состоит в том, что в качестве объекта выступает не продуктовый портфель, а портфель клиентов компании. Анализ потребителей и их предпочтений является фундаментом формирования маркетинга взаимоотношений для управляющей организации на рынке ЖКУ.

Поскольку спецификой рынка ЖКУ является коллективное потребление жилищных услуг, соответственно, групповым потребителем является конкретный многоквартирный дом (далее - МКД). Сегментация таких коллективных потребителей для разных управляющих компаний имеет свои отличия.

Так, для управляющей компании, в управлении которой находится много домов (как чаще всего и реализуется на практике), возможно проводить сегментацию по специфическим характеристикам жилого фонда, что позволит дифференцировать маркетинговые взаимоотношения для каждого сегмента. В качестве критериев сегментации можно предложить:
- возраст МКД (старый фонд, новые застройки - как показывает практика - в разных домах - разный контингент потребителей);

- степень износа инженерных коммуникаций (высокий износ тесно связан с большим числом аварийных ситуаций на внутридомовых сетях, социальной напряженностью в коммуникациях в связи недовольством собственников, высоким уровнем издержек на содержание и текущий ремонт);

- техническое состояние здания и придомовой территории;

- уровень комфортности жилья (эконом, комфорт, элитное жилье);

- стоимость жилья в данном МКД на рынке недвижимости;

- степень активности проживающих в МКД (наличие Совета МКД, старших по дому и по подъездам и т. д.).

От данных параметров зависят все маркетинговые переменные взаимоотношений, а также конкретный перечень умных технологий, разрабатываемых УК и предлагаемых на согласование общим собраниям собственников (далее - ОСС). Естественно, что старый фонд МКД более затратен для УК и жильцов с точки зрения внедрения умных инноваций.

Для ТСЖ или ТСН, в управлении которых находится один дом (что нормативно закреплено в ст. 136 Жилищного кодекса РФ [Жилищный кодекс ..., 2020], проведение сегментации по жилому фонду невозможно, а значит, маркетинговые взаимоотношения 
будут выстраиваться с одним коллективным потребителем.

Тем не менее независимо от числа МКД управляющая организация, в том числе ТСЖ и ТСН, должна осуществлять маркетинговое исследование потребителей и их запросов на регулярной основе путем устных опросов, анкетирования, наблюдения поведения собственников, результатов обсуждения на общих собраниях, анализа заявок жильцов. Высокая степень удовлетворенности потребителей ЖКУ возможна лишь при полном понимании их истинных потребностей управляющей организацией. Для этого при разработке стратегического плана мероприятий по внедрению умных технологий целесообразно воспользоваться адаптированной применительно к исследуемому рынку «пирамидой потребностей» А. Маслоу [Маслоу, 2006].

По нашей гипотезе, услуга ЖКХ может удовлетворять все уровни потребностей, поэтому ее совершенствование и внедрение умных технологий может и должно осуществляться в направлении восхождения от удовлетворения первой, базовой нужды к удовлетворению высшей потребности (рис. 2):

Первый уровень - обеспечение выживания человека в доме, удовлетворения элементарной физиологии. Покупатель жилищно-коммунальной услуги в процессе покупки и по- требления руководствуется, прежде всего, утилитарными мотивами: желанием и намерением приобрести достаточный или минимально необходимый объем ЖКУ по приемлемой цене для удовлетворения базовых физиологических нужд [Цифровая Россия ... , 2014, с. 128-129]. Качество всех коммунальных ресурсов должно соответствовать нормативным значениям: горячая вода должна быть не менее $60^{\circ}$, в квартире зимой температура не должна опускаться ниже $22^{\circ}$ (в угловых квартиpax $\left.-24^{\circ}\right)$, напряжение в электросети должно быть в допустимом диапазоне 210-220B и т. д. К умным технологиям, предлагаемым на данном уровне, можно отнести энергосберегающие технологии, позволяющие снизить размер оплаты за ЖКУ: индивидуальные приборы учета ресурсов воды, газа, электроэнергии (в том числе технологий удаленной передачи данных), автоматизированные системы учета тепловой энергии с атмосферными датчиками, энергосберегающие светильники, датчики движения, звука, освещенности и т. д.

Второй уровень - потребность в безопасности. Сегодня у жильцов есть много опасений перед возможными неприятными событиями (аварии, затопления, сосульки и наледь и т. д.). Обеспечение безопасности - одна из важнейших функций управляющих организаций наряду с обеспечением надлежащего ка-

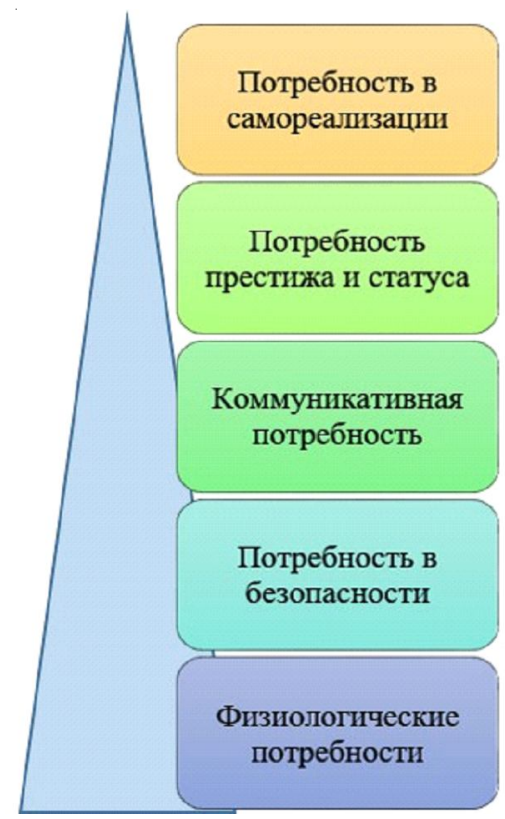
-Участие в ОСС, активная вовлеченность в дела дома,
предложение идей по улучшению обслуживания
дома, совместное формирование общих ценностей

-Потребность в дополнительных услугах комфорта и престижа: видеонаблюдение, консьержки, охрана, раздельный сбор мусора, шлагбаумы, парковки и т.д.

-Полный и прозрачный обмен информацией с управляющей организацией (по ЖКУ, АДО, тарифам, ОСС и т.д.)

- Отсутствие аварийных ситуаций, безопасность конструкций дома и инженерных сетей, безопасность нахождения на придомовой территории

-Потребность в наличии обязательного набора коммунальных ресурсов надлежащего качества: вода, свет, газ, тепло, водоотведение

Рис. 2. Пирамида потребностей потребителей ЖКУ

Примечание. Составлено автором. 
чества ЖКУ. На данном уровне управляющая организация может предложить к внедрению системы аварийного отсечения коммунальных ресурсов - датчики утечки воды, газа, датчики задымленности, установку систем антиобледенения на крыши домов и т. д.

Третий уровень по А. Маслоу - потребность в коммуникациях. В данном контексте маркетинг взаимоотношений УК и ТСЖ наиболее полно проявляется посредством обеспечения полной прозрачности информационного обмена с жильцами. Должен быть обеспечен полный доступ к информации об управляющей организации, аварийно-диспетчерской службе, телефонах персонала, графике работы, тарифах на ЖКУ, отчетах о проделанной работе, планируемых работах и т. д. К данному уровню потребностей можно отнести такие умные технологии, как интерактивный сайт управляющей организации, социальные сети, мобильные приложения и мессенджеры.

Четвертый уровень обычно трактуется как потребность в общественном признании, уважении. Это уровень статуса, стиля и образа жизни. Применительно к рынку ЖКХ можно сказать, что в соответствии с данным уровнем обычно приобретается недвижимость уровня «комфорт» и «элит». Многоквартирные дома старой застройки невозможно превратить в элитное жилье, однако можно максимально улучшить параметры здания и прилегающей территории, приблизив их, насколько это возможно, к уровню «комфорт». Очевидно, что здесь уместно говорить о расширении услуг управляющей организации (при совместном решении с жильцами) от стандартного минимального набора к дополнительным услугам и умным технологиям - видеонаблюдение, видеодомофон, охрана, консьержки, огораживание территории, парковки, шлагбаумы, фонтаны, системы автополива растенй и т. д.).

Пятый уровень - потребность в самоактуализации. На данном уровне человек нацелен не на покупку товаров / услуг, а на развитие собственного духовного потенциала, миссии, личностный рост. Тем не менее для потребителей ЖКУ можно предложить следующую трактовку: на данном уровне жильцы в качестве партнеров активно участвуют в управлении домом как общим объектом для всех стейкхолдеров, поскольку осознают собствен- ную ответственность, а также готовы транслировать собственный позитивный опыт и ценности другим потребителям. В данном контексте актуальны все те же цифровые коммуникации посредством сайта, социальных сетей, мобильных приложений и мессенджеров.

Как видно из рисунка 2, удовлетворение каждой более высокой потребности сопровождается повышением доверия и степени вовлеченности жителей в процесс формирования ЖКУ более высокого порядка. При этом выполняется условие, обозначенное самим Маслоу: переход на новый уровень возможен только при полном удовлетворении предыдущего. Очевидно, что предлагать жильцам многоквартирных домов мобильные приложения для удобства коммуникаций нецелесообразно, пока инженерные сети дома находятся в аварийном состоянии. Таким образом, данная схема демонстрирует стратегический вектор выстраивания маркетинга взаимоотношений управляющей организации, где генеральная цель (видение будущего) - удовлетворение, в том числе с помощью умных технологий, потребностей 5-го уровня, когда собственники осознают себя партнерами и совместно с УК или ТСЖ строят долгосрочные эффективные отношения. Для реализации данной цели необходимо последовательное (в соответствии с предложенной моделью потребностей) решение следующих задач:

1. Улучшение качества обслуживания предоставление эталонных жилищно-коммунальных услуг.

2. Снижение числа аварийных ситуаций и затрат на их устранение.

3. Проведение совместно с собственниками всех возможных мероприятий по энергосбережению в ближайшие 3-5 лет (утепление дома и кровли, установка стеклопакетов в подъезды, установка умных систем управления инженерными системами).

4. Повышение эффективности коммуникаций с жильцами и партнерами, обеспечение прозрачного информационного обмена.

5. Обновление и улучшение характеристик общедомового имущества с целью повышения комфортности проживания. Данные меры осуществляются за счет эффективного использования средств фонда капитального ремонта (например, на специальном счете 
C.В. Федорова. Роль маркетинга взаимоотношений в продвижении умных технологий на рынке услуг ЖКХ

капитального ремонта дома) путем совместного выбора с собственниками перечня работ (в том числе по внедрению умных технологий) и подрядчиков.

Тактический уровень планирования включает в себя комплекс действий, маркетинговых технологий и инструментов, необходимых для достижения стратегической установки управляющей организации и улучшения партнерских отношений с потребителями.

Классические точки взаимодействия с потребителями - маркетинговая смесь «4Р» Джерома Маккарти, впоследствии популяризованная Ф. Котлером: продукт, цена, каналы сбыта, продвижение [Котлер и др., 2012]. Для сферы услуг часто добавляют пятую, шестую и седьмую «Р»-people (люди, персонал), process (процесс), physical surround (физическая среда оказания услуги), хотя их использование относится к дискуссионным вопросам. Данные элементы - управляемые со стороны организации переменные, они же - тактические маркетинговые инструменты.

В процессе упомянутой выше трансформации рынков в рынки покупателей модель «4Р» и ее вариации теряют свою эффективность, поскольку существенно меняется поведение потребителей. В 1990 г. Робертом Ф. Лотерборном была предложена новая маркетинговая модель (концепция)
«4С», в которой осуществлен перенос акцента маркетинговой деятельности с продукта компании на потребителя. Элементы «4С» следующие:

1. Customer needs and wants (нужды и желания потребителей).

2. Cost (расходы покупателя).

3. Convenience (удобство и комфорт потребителя).

4. Communication (коммуникации) [Цзян и др., 2015, с. 143].

Для внедрения умных технологий на рынке ЖКУ необходим симбиоз двух моделей в модель «4P-4С», поскольку маркетинг взаимодействия предполагается взаимные выгоды в процессе совместного формирования ценности обеими сторонами (см. таблицу).

Следует отметить, что в концепции управления взаимоотношениями с потребителями делается больший акцент на коммуникативную составляющую, чем в классической теории маркетинга. Основой тактического планирования коммуникаций с целевыми группами являются:

- количественный и качественный состав целевых сегментов (определение потребностей, уровня притязаний, покупательской способности и т. д.);

- структура и содержание коммуникационных обращений;

Таблииа

Адаптация моделей «4Р» и «С» для управляющих организаций на рынке ЖКУ

\begin{tabular}{|c|c|c|}
\hline «4P» & $\langle 4 \mathrm{P}-4 \mathrm{C}\rangle$ & $\langle 4 \mathrm{C} »$ \\
\hline $\begin{array}{c}\text { Product } \\
\text { (жилищно- } \\
\text { коммунальная } \\
\text { услуга) }\end{array}$ & $\begin{array}{l}\text { Совместно создаваемая потребительская ценность (утверждение соста- } \\
\text { ва общего имущества, формирование перечня внедряемых умных тех- } \\
\text { нологий и доп. услуг, перечня планируемых работ по благоустройству, } \\
\text { капитальному ремонту и т. д.) }\end{array}$ & $\begin{array}{l}\text { Customer needs } \\
\text { and wants } \\
\text { (нужды и желания } \\
\text { потребителей } \\
\text { ЖКУ) }\end{array}$ \\
\hline $\begin{array}{c}\text { Price } \\
\text { (тарифы } \\
\text { на ЖКУ) }\end{array}$ & $\begin{array}{l}\text { Согласование с жильцами и утверждение на общем собрании собствен- } \\
\text { ников тарифов на содержание и текущий ремонт, капитальный ремонт, } \\
\text { дополнительных целевых взносов на внедрение умных технологий, го- } \\
\text { довых смет }\end{array}$ & $\begin{array}{c}\text { Cost } \\
\text { (размер взносов } \\
\text { потребителя } \\
\text { на ЖКУ) }\end{array}$ \\
\hline $\begin{array}{l}\text { Place } \\
\text { (место оказа- } \\
\text { ния ЖКУ } \\
\text { (МКД)) }\end{array}$ & $\begin{array}{l}\text { Совместная разработка доступной среды сервисного обслуживания по- } \\
\text { требителей (оперативное аварийно-диспетчерское обслуживание с ис- } \\
\text { пользованием умных систем, организация всех доступных способов } \\
\text { оплаты ЖКУ - сайт, мобильные приложения) }\end{array}$ & $\begin{array}{l}\text { Convenience } \\
\text { (удобство } \\
\text { для потребителя) }\end{array}$ \\
\hline $\begin{array}{c}\text { Promotion } \\
\text { (продвижение } \\
\text { ЖКУ населе- } \\
\text { нию) }\end{array}$ & $\begin{array}{l}\text { Обмен информацией через все доступные каналы коммуникаций с це- } \\
\text { лью построения доверительных отношений сотрудничества (информа- } \\
\text { ционные стенды в подъездах МКД, стационарная и мобильная теле- } \\
\text { фонная связь, мобильные приложения (Viber, Whats App), интерактив- } \\
\text { ный сайт УО, ГИС ЖКХ и т. д.). Разъяснительная работа с населением, } \\
\text { опросы, общие собрания собственников }\end{array}$ & $\begin{array}{c}\text { Communication } \\
\text { (двухсторонние } \\
\text { коммуникации с } \\
\text { потребителем) }\end{array}$ \\
\hline
\end{tabular}

Примечание. Составлено автором. 
- выбор наименее затратных каналов коммуникаций, распределение ресурсов управляющей организации.

Поскольку любые издержки, в том числе рекламного характера, должны закладываться в годовую смету и согласовываться с жильцами, большие затраты на коммуникационные мероприятия практически исключены. Поэтому перед управляющей организацией также стоит сложная задача поиска эффективных низкобюджетных площадок взаимодействия с потребителями.

\section{Заключение}

Сфера ЖКХ считается консервативной и закрытой новым технологиям отраслью, характеризующейся значительным технологическим отставанием и недофинансированием.

Эффективность развития умных технологий в жилищно-коммунальном секторе полностью определяется запросами и предпочтениями потребителей, степенью их удовлетворенности и вовлеченности в развитие данного сектора, при этом отбор, финансирование и внедрение умных технологий в управление многоквартирными домами де-юре невозможны без согласования с жильцами на общих собраниях собственников.

Поэтому развитие умных технологий на рынке ЖКУ может идти только по пути внедрения в работу управляющей организации современных инструментов маркетинга взаимоотношений, выявления актуальных потребностей жителей и конструирования конкретных умных технологий, соответствующих запросам и ожиданиям целевых аудиторий.

\section{СПИСОК ЛИТЕРАТУРЫ}

Астратова, Г. В. Комплексный портрет потребителя услуг ЖКХ мегаполиса (на примере г. Екатеринбурга) / Г. В. Астратова, Е. В. Баженова // Гуманитарные, социально-экономические и общественные науки. - 2014. - № 5-2. C. $127-130$.

Бабкина, А. Недофинансирование системы ЖКХ составляет 2-2,5 триллиона рублей / А. Бабкина. - Электрон. текстовые дан. - Режим доступа: https://nversia.ru/news/nedofinansirovanie- sistemy-zhkh-sostavlyaet-2-2-5-trilliona-rubley (дата обращения: 19.12.2019). - Загл. с экрана.

Бондаренко, В. А. Истоки появления маркетинга, ориентированного на долгосрочные взаимоотношения с потребителем / В. А. Бондаренко // Евразийский союз ученых. - 2015. - № 21(11). - C. 31-32.

Гембл, П. Маркетинг взаимоотношений с потребителями / П. Гембл, М. Стоун, Н. Вудкок ; пер. с англ. В. Егорова. - М. : ФАИР-ПРЕСС : ГРАНД, 2002. $-511 \mathrm{c}$.

Жилищный кодекс Российской Федерации от 29.12.2004 № 188-Ф3 (ред. от 06.02.2020), Ст. 136. - Доступ из справ.-правовой системы «КонсультантПлюс».

Коваль, С. П. Энергосбережение в ЖКХ: 96 способов / С. П. Коваль. - Электрон. текстовые дан. Режим доступа: http://portal-energo.ru/articles/ details/id/40 (дата обращения: 20.12.2019).

Котлер, Ф. Маркетинг и менеджмент: научное издание / Ф. Котлер, К. Л. Келлер. - 12-е изд. СПб. : Питер, 2012. -816 с.

Маслоу, А. Мотивация и личность : пер. с англ. / А. Маслоу. - 3-е изд. - СПб. : Питер, 2012. $352 \mathrm{c}$.

Осведомленность россиян о реформе ЖКХ : отчет по результатам исследования для Некоммерческого партнерства «Национальный центр общественного контроля в сфере жилищнокоммунального хозяйства «ЖКХ Контроль». Электрон. текстовые дан. - Режим доступа: http://fondgkh.ru/wp-content/uploads/2017/04/ VTSIOM Fond-ZHKH Otchet Sentyabr.pdf. (дата обращения: 12.12.2019). - Загл. с экрана.

Таппасханова, Е. О. Концепция партнерства или концепция маркетинга взаимоотношений / Е. О. Таппасханова, Д. А. Битохова, Ф. А. Бифова // Научные дискуссии. - 2017. - № 1. C. 64-73.

Цзян, Чао. Развитие моделей комплекса маркетинга: 4P, 7P, 4C, 4V и 4R / Чао Цзян, Е. Б. Кметь // Экономическая наука сегодня: теория и практика : сб. материалов III Междунар. науч.практ. конф. - Чебоксары : [б. и.], 2015. C. $143-148$.

Цифровая Россия: новая реальность: отчет компании McKinsey. Июль 2017 г. / А. Аптекман [и др.]. - Электрон. текстовые дан. - Режим доступа: https://www.mckinsey.com/ /media/ mckinsey/locations/europe $\% 20$ and $\% 20$ middle $\%$ 20east/russia/our\%20insights/digital\%20russia/ digital-russia-report.ashx (дата обращения: 15.12.2019). - Загл. с экрана.

Bruhn, M. Relationship Marketing: Management of Customer Relationships / M. Bruhn. - [S. 1.] : Pearson Education Ltd, 2003. - 289 p. 
Fedorova, S. The Issues of Sustainable Development of the Housing and Utilities Market / S. Fedorova, N. Mushketova // Advances in Economics, Business and Management Research. - 2019.Vol. 83. - P. 452-456. - DOI: https://doi.org/ 10.2991/cssdre-19.2019.88.

Shani, D. Exploiting Niches Using Relationship Marketing / D. Shani, S. Chalasani // Journal of Consumer Marketing. - 1992. - Vol. 9, No. 3. - P. 33-42. DOI: https://doi.org/10.1108/07363769210035215.

\section{REFERENCES}

Astratova G.V., Bazhenova E.V. Kompleksnyy portret potrebitelya uslug $\mathrm{ZhKKh}$ megapolisa (na primere g. Ekaterinburga) [A Comprehensive Portrait of the Consumer of Housing and Utilities Services in the Megapolis (On the Example of Yekaterinburg)]. Gumanitarnye, sotsialnoekonomicheskie i obshchestvennye nauki [Humanities, Socio-Economic and Social Sciences], 2014, no. 5-2, pp. 127-130.

Babkina A. Nedofinansirovanie sistemy ZhKKh sostavlyaet 2-2,5 trilliona rubley [Underfunding of the Housing and Utilities System Is 22.5 Trillion Rubles]. URL: https://nversia.ru/ news/nedofinansirovanie-sistemy-zhkhsostavlyaet-2-2,5-trilliona-rubley/ (accessed 19 December 2019).

Bondarenko V.A. Istoki poyavleniya marketinga, orientirovannogo na dolgosrochnye vzaimootnosheniya s potrebitelem [The Origins of Marketing Focused on Long-Term Relationships with Consumers]. Evraziyskiy soyuz uchenykh [Eurasian Union of Scientists], 2015, no. 2-1 (11), pp. 31-32.

Gembl P., Stoun M., Vudkok N. Marketing vzaimootnosheniy s potrebitelyami [Marketing of Relationships with Customers]. Moscow, FAIR-PRESS Publ., GRAND Publ., 2002. 511 p.

Zhilishchnyy kodeks Rossiyskoy Federatsii ot 29.12.2004 № 188-FZ (red. ot 06.02.2020), St. 136 [Housing Code of the Russian Federation Dated December 29, 2004 no. 188-FZ of (Amended on February 6, 2020), Article 136]. Access from Reference Legal System "KonsultantPlyus".

Koval S.P. Energosberezhenie v ZhKKh: 96 sposobov [Energy Saving in Housing and Utilities: 96 Ways]. URL: http://portal-energo.ru/articles/ details/id/40 (accessed 20 December 2019).

Kotler F., Keller K.L. Marketing $i$ menedzhment: nauchnoe izdanie [Marketing and Management]. Saint Petersburg, Piter Publ., 2012. 816 p.
Maslou A. Motivatsiya i lichnost: per. s angl. [Motivation and Personality. Translated from English]. Saint Petersburg, Piter Publ., 2012. 352 p.

Osvedomlennost rossiyan o reforme ZhKKh: otchet po rezultatam issledovaniya dlya Nekommercheskogo partnerstva «Natsionalnyy tsentr obshchestvennogo kontrolya $v$ sfere zhilishchno-kommunalnogo khozyaystva «ZhKKh Kontrol» [Russian Awareness of Housing and Communal Services Reform. Report on the Research Results for the Non-Profit Partnership "National Center for Public Control in Housing and Communal Services" "Housing and Communal Services Control"]. URL: http:// fondgkh.ru/wp-content/uploads/2017/04/ VTSIOM Fond-ZHKH Otchet Sentyabr.pdf (accessed 12 December 2019).

Tappaskhanova E.O., Bitokhova D.A., Bifova F.A. Kontseptsiya partnerstva ili kontseptsiya marketinga vzaimootnosheniy [The Concept of Partnership or the Concept of Relationship Marketing]. Nauchnye diskussii [Scientific Discussions], 2017, no. 1, pp. 64-73.

Czjan Chao, Kmet E.B. Razvitie modeley kompleksa marketinga: 4P, 7P, 4C, 4V i 4R [Development of Models of the Marketing Complex: 4P, 7P, 4C, $4 \mathrm{~V}$ and 4R]. Ekonomicheskaya nauka segodnya: teoriya i praktika: sb. materialov III Mezhdunar. nauch.-prakt. konf. [Economics Today: Theory and Practice. Proceedings of the $3^{\text {rd }}$ International Scientific and Practical Conference]. Cheboksary, [s.n.], 2015, pp. 143-148.

Aptekman A., Kalabin V., Klintsov V., Kuznetsova E., Kulagin V., Yasenovets I. Tsifrovaya Rossiya: novaya realnost: otchet kompanii McKinsey. Iyul 2017 g. [Digital Russia: New Reality. Report from McKinsey Company, July 2017]. URL: https://www.mckinsey.com/ /media/mckinsey/ locations/ europe $\% 20$ and $\% 20$ middle $\% 20$ east/ russia/our\%20insights/digital\%20russia/digitalrussia-report.ashx (accessed 15 December 2019).

Bruhn M. Relationship Marketing: Management of Customer Relationships. [S. 1.], Pearson Education Ltd, 2003. 289 p.

Fedorova S., Mushketova N. The Issues of Sustainable Development of the Housing and Utilities Market. Advances in Economics, Business and Management Research, 2019, vol. 83, pp. 452456. DOI: https://doi.org/10.2991/cssdre19.2019.88.

Shani D., Chalasani S. Exploiting Niches Using Relationship Marketing. Journal of Consumer Marketing, 1992, vol. 9, no. 3, pp. 33-42. DOI: https:// doi.org/10.1108/07363769210035215. 


\section{УПРАВЛЕНИЕ ЭКОНОМИЧЕСКИМ РАЗВИТИЕМ}

\section{Information About the Author}

Svetlana V. Fedorova, Senior Lecturer, Department of Marketing, Volgograd State University, Prosp. Universitetsky, 100, 400062 Volgograd, Russian Federation, fedorovasv@volsu.ru, https://orcid.org/0000-0002-9347-5931

\section{Информация об авторе}

Светлана Владимировна Федорова, старший преподаватель кафедры маркетинга, Волгоградский государственный университет, просп. Университетский, 100, 400062 г. Волгоград, Российская Федерация, fedorovasv@volsu.ru, https://orcid.org/0000-0002-9347-5931 